\title{
Mixed IgG, IgM and IgA Cryoglobulin Response in Human Typhoid Patients
}

\author{
Ibrahim M.S. Shnawa and Ahmed. J. Alsarhan \\ University of BabylonCollege of ScienceDepartment of Biology
}

\begin{abstract}
Cryoglobulin response appeared within one to four days at $4^{\circ} \mathrm{C}$ and redissolved at 37 and $45^{\circ} \mathrm{C}$ within 1/2 to 2.1/2 hrs. The texture of the cryoglobulin was gelatinous 49:60( $81.7 \%$ ) and flocculent 8: 60 ( $13.3 \%$ ). The mean of cryocrit percent among typhoid patients was $6.1 \%$ while among control was 0.2 Cryoglobulin response was associated with RF in 28:57 (49.12\%) among typhoid patients sera and nil among controls. The immunofixation studies using radial immunodiffusion in gel have shown that type of cryoglobulin response was of mixed type IgG-IgM-IgA. The RF associated cryoglobulinemia have shown higher IgG concentration than non RF associated cryoglobulin. The Ig classes have shown individual variations . S.typhi $O$ agglutinins were 46:57 (80.7\%) in typhoid. Thus, type IIIsecondary mixed IgG-IgM-IgA cryoglobulinemia associated with typhoid patients sera with S.typhi O specific cold agglutinins as well .
\end{abstract}

Keywords: Cryoglobulin, Typhoid, IgM, IgA, IgG

\section{Introduction}

Shnawa and Hindi 1996 (1) have been documented the role of Salmonella agglutinins as a marker for enteric fever and typhoid fever in PUO patients .Shnawa and Al-Amide 2004 (2) have been reported the humoral immune profiles of typhoid in seroepidemiologic sense .Shnawa and Al-Sadi 2001(3) have been tackling the gut mucosal S.typhi specific agglutinin as probe for typhoid infection .Abd2000 (4) have been tried to compare mucosal and systemic immune responses in typhoid patients. Al-Amar 2006 (5) has been investigating humoral and cellular, mucosal and systemic immune responses of typhoid patients . The present work was intended to investigate the cryoglobulinemia secondary to natural human typhoid disease .

\section{Materials and methods}

1-Patients :Atotal of 118 enteric fever suspects on clinical bases were elected as a patients test group . thirty apparently normal subjects were elected as controls (6) .

2-Samples : Each of the patients and controls were subjected to $5 \mathrm{ml}$ samples collection of blood, $0.5 \mathrm{ml}$ for culture study and $4.5 \mathrm{ml}$ for saving sera (7).

3-Culture study : The $0.5 \mathrm{ml}$ blood sample were in biphasic brain infusion culture for up to 7 days at $37^{\circ} \mathrm{C}$ using microculture device in beju bottles of $5 \mathrm{ml}$ size (8)

4-Immunodiagnosis : Each of patients and controls were tested by S.typhiO and S.typhi $\mathrm{H}$ agglutinin levels in their sera and by lateral flow chromatographic immunoassay for IgM and IgGS.typhi specific immunoglobulins $(9,10)$.

5-Cryoglobulinemia assay :Cryocrit percent, cryoglobulin separation and identification, immunofixation as well as RF association were performed as in $(11,12)$.

1- Typhoid immunodiagnosis :

\section{Results}

S.typhi $\mathrm{O}$ and $\mathrm{H}$ specific agglutinins equal or more than 160 titers were 79:118 enteric fever suspect patients of which 60:118 were showing either $\operatorname{IgG}$ or IgM specific for typhoid using lateral flow chromatography immunoassay. They were 60:118 S. typhi infected enteric fever (typhoid patients ). There were $66.9 \%$ of the test group confirm the clinical disease picture ( Table 1 ).

2-Cryoprotein response :

A total of 57:60 (95\%) were showing cryoprotein response as cryoprecipitate within one to four days and cryocrit percent of $6.1 \%$. The cryoprotein precipitate were showing physical texture of gelatinous and flocculent and soluble at $37^{\circ} \mathrm{C}$ with solubility time of $1 / 2$ to $2.1 / 2 \mathrm{hrs}$, Re cooling at $4^{\circ} \mathrm{C}$ and the preparations were repricipitated (Table 2 ).

3- Cryoglobulin response :

The precipitation at $4{ }^{\circ} \mathrm{C}$, solubility at $37^{\circ} \mathrm{C}$ and repricipitate at $4^{\circ} \mathrm{C}$ as well as the physical texture are consistent with the cryoglobulin responses . 
4- Rhematoidfactor :

The cryoglobulin were of two types .Cryoglobulin with and without rheumatoid factor response with 28:57 (49.12\%) and 29:57 (50.9\%) respectively. The titer means were 7.7 , 7.2 and 7.4 for male , female and total respectively .

5- Immunofixation :

The cryoglobulin responses were of mixed type IgG-IgM-IgA type. The RF associated cryoglobulin were higher IgG - IgM and IgA concentration than non RF associated response as shown on 15 patients of each of the two groups ( Table 3 ) .

6- S.typhi O agglutinins :

A 46:57 (80.7\%) of the patients were showing S.typhi cold agglutinin responses .

7- Individuals variations in cryoglobulinresponses :

The figures $(1,2,3)$ was showing the existence of individuals variations in the herd cryoglobulin responses. The $\mathrm{RF}$ associated were with higher $\operatorname{IgG}-\operatorname{IgM}$ and $\operatorname{IgA}$ concentrations than of the non RF associated

Table 1 : Diagnosis of Typhoid by Laboratory Methods

\begin{tabular}{|l|l|}
\hline Method & Percent \% \\
\hline Blood culture & $3: 118(2.5 \%)$ \\
\hline Widal test & $79: 118(66.9 \%)$ \\
\hline $\begin{array}{l}\text { Lateral flow chromatographic immunoassay (IgM - } \\
\text { IgG ) }\end{array}$ & $60: 118(50.8 \%)$ \\
\hline
\end{tabular}

Table 2 : The biophysical characters of cryoglobulin in typhoid patients se

\begin{tabular}{|c|c|c|c|c|c|}
\hline \multicolumn{6}{|c|}{ A- $\quad$ Appearance time } \\
\hline Seq & First day & Second day & Third day & Fourth day & Percent $\%$ \\
\hline 1 & 14 & & & & $14: 57(24.6 \%)$ \\
\hline 2 & & 19 & & & 19:57(33.3\%) \\
\hline 3 & & & 22 & & $22: 57(38.6 \%)$ \\
\hline 4 & & & & 2 & $2: 57(3.5 \%)$ \\
\hline \multicolumn{6}{|c|}{ B- $\quad$ Texture } \\
\hline \multicolumn{3}{|c|}{ Precipitate type } & \multicolumn{2}{|c|}{ Percent $\%$} & \\
\hline \multicolumn{3}{|c|}{ Gelatinous } & \multicolumn{2}{|c|}{$49: 60(81.7 \%)$} & \\
\hline \multicolumn{3}{|c|}{ Flocculent } & \multicolumn{2}{|c|}{$8: 60(13.3 \%)$} & \\
\hline \multicolumn{3}{|c|}{ Nile } & \multicolumn{2}{|c|}{$3: 60(5 \%)$} & \\
\hline \multicolumn{3}{|c|}{ C- $\quad$ Solubility } & & & \\
\hline \multicolumn{3}{|c|}{ Temperature } & \multicolumn{2}{|c|}{ Percent $\%$} & \\
\hline \multicolumn{3}{|c|}{$37^{\circ} \mathrm{C}$} & \multicolumn{2}{|c|}{$53: 57(93 \%)$} & \\
\hline \multicolumn{3}{|c|}{$45^{\circ} \mathrm{C}$} & & \\
\hline \multicolumn{3}{|c|}{ D- $\quad$ Cryocrit percent $\%$} & \multicolumn{2}{|c|}{$4: 57(7 \%)$} & \\
\hline \multicolumn{2}{|c|}{ Patients } & Mean & \multicolumn{2}{|c|}{ Median } & Range \\
\hline \multicolumn{2}{|c|}{ Male } & $6.413 \%$ & \multicolumn{2}{|c|}{$5 \%$} & $45 \%$ \\
\hline \multicolumn{2}{|c|}{ Female } & $5.806 \%$ & \multicolumn{2}{|l|}{$6 \%$} & $8.5 \%$ \\
\hline \multicolumn{2}{|c|}{ Total } & $6.1 \%$ & \multicolumn{2}{|c|}{$5.5 \%$} & $45 \%$ \\
\hline Cont & & Mean & \multicolumn{2}{|c|}{$\frac{5.5 \%}{\text { Median }}$} & Range \\
\hline Male & & $0.156 \%$ & $0 \%$ & & $1 \%$ \\
\hline Fem & & $0.214 \%$ & $0 \%$ & & $1 \%$ \\
\hline Total & & $0.2 \%$ & $0 \%$ & & $1 \%$ \\
\hline
\end{tabular}

Table 3 : Rheumatoid factor with cryoglobulin isotypes among typhoid

\begin{tabular}{|l|l|l|l|l|}
\hline \multirow{2}{*}{$\begin{array}{l}\text { Immunoglobulins } \\
\text { Classes }\end{array}$} & & Mean & Median & Range \\
\hline \multirow{3}{*}{ IgG } & $\mathrm{RF}+$ & 10.338 & 9.923 & 7.123 \\
\cline { 2 - 5 } & $\mathrm{RF}+$ & 6.429 & 6.156 & 5.356 \\
\hline \multirow{3}{*}{ IgM } & $\mathrm{RF}+$ & 1.227 & 1.025 & 1.6 \\
\cline { 2 - 5 } & $\mathrm{RF}-$ & 0.745 & 0.789 & 1.137 \\
\hline \multirow{2}{*}{ IgA } & $\mathrm{RF}+$ & 1.641 & 1.653 & 2.358 \\
\cline { 2 - 5 } & $\mathrm{RF}-$ & 0.928 & 0.875 & 1.51 \\
\hline
\end{tabular}

Reference value*

Normal subjects

$0.08 \mathrm{mg} \backslash \mathrm{ml}$

Mixed cryoglobulin I $\quad 5.0 \mathrm{mg} / \mathrm{ml}$

Mixed cryglobulin II $\quad 1.0 \mathrm{mg} / \mathrm{ml}$

Abnormal cryoglobulin up to $25 \mathrm{mg} / \mathrm{ml}$ 


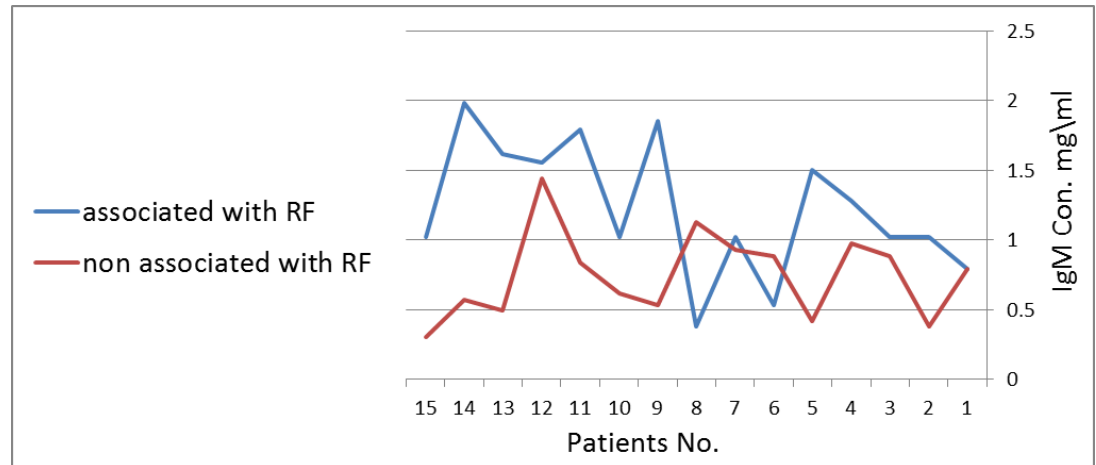

Fig 1 : Individuals variations in IgM concentration

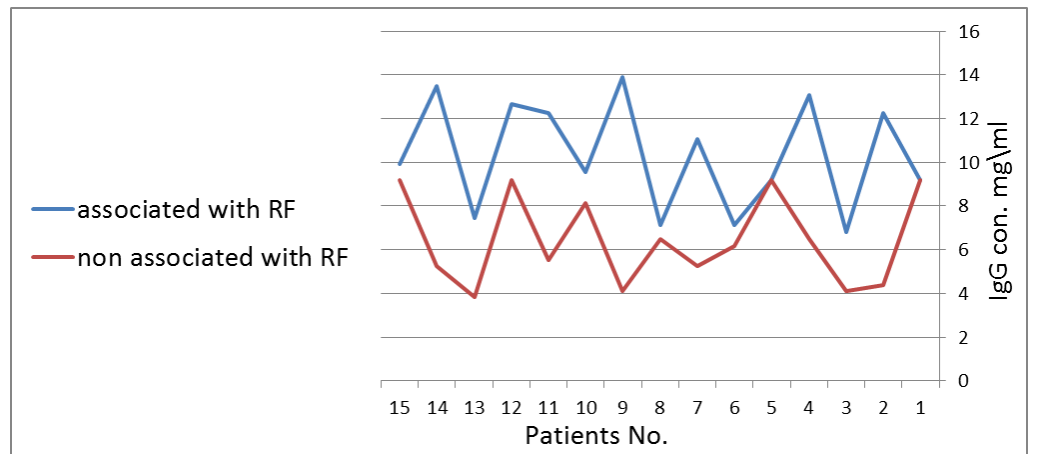

Fig 2 : Individuals variations in IgG concentration

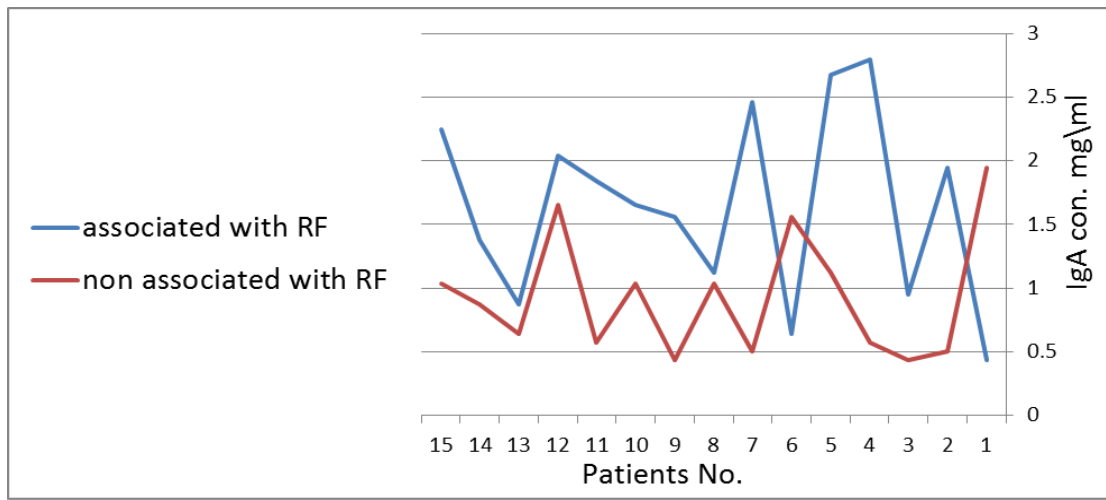

Fig 3 : individuals variations in IgA concentration

\section{Discussion}

Intracellular viral, bacterial and protozoal infection in man may be coexisted with secondary mixed cryoglobulin response ( 13 ). Leprosy, tuberculosis, some scattered individuals cases of gram negative intracellular pathogen such as Salmonella and Brucella have shown secondary mixed cryoglobulinemia $(13,14,15,16)$.

Tuberculosis natural and induced secondary mixed cryoglobulinemia were reported in this area $(13,16)$. Present work was intended to report natural mixed cryoglobulinemia associated with typhoid .

The major immune features of this cryoglobulinemia

1- Serum cryoglobulin appeared within $1-4$ days at $4{ }^{\circ} \mathrm{C}$ and redissolved at 37 and $45^{\circ} \mathrm{C}$.

2- It is gelatinous and flocculent texture .

3- It is of mixed immunoglobulin classes IgG-IgM-IgA

4- RF and non RF associated .

5- S.typhi $\mathrm{O}$ cold agglutinin response in most of the cases .

The cryoglobulin( feature 1-5 ) are consistent with that reported in gram negative intracellular infection and that reported in tuberculosis patients (12).

Thus, type III secondary mixed cryoglobulinemia are being reported among typhoid patients, taking in consideration that search in literature have indicate absence of planed systemic study about typhoid associated cryoglobulinemia . 


\section{References}

[1]. Shnawa I.M.S. and Hindi W.A.Z. ( 1996 ) . Febrile circulating agglutinins . Al-Techniq . 31:29-35 .

[2]. Shnawa, I. M. S. and Al-Amide, B. H. (2004). Humoral immune profiles infection form and epidemiology of typhoid. J. Babylon. Univ. 9(3) :554-561.

[3]. Shnawa I.M.S. and Al-Sadi M.A.K. ( 2001 ) .Gut mucosal immunoglobulin: Separation ,partial characterization and utilityInfection probe.Iraq.J.Micrbiol.13(3);57-70.

[4]. Abid ,F.J., (2000). Comparative study between local and systemic humoralimmune response in typhoid patient . M. Sc. Thesis . Babylon University.

[5]. Al-Amar M.H.A. ( 2006 ) . Some aspects of specific immunity for S.typhi in typhoid patients and in rabbits. Ph.D. Thesis , Babylon University, College of science, Department of Biology .

[6]. Brook G.F. , Carroll K.C. , Butel J.S. , Morse S.A. and Mietzner T.A. ( 2010 ) . Jawtz ,Melnick and Adelbergs . Medical Microbiology 25thed.Lange Co. New York .

[7]. Hay, F. C. and Westwood O. M. R. (2002). Practical immunology. 4th ed., PP:350. Blackwell Co. U.K.

[8]. Shnawa I.M.S. and Al-Dulimi K.A.H.2001.Pediatric bacterial blood stream infections.Iraq.J.Scie.42B(2):8-22.

[9]. Mahon, C.R. and Tice, D. ( 2006 ). Clinical Laboratory Immunology Printice-Hall . Clinical Laboratory Science Series

[10]. Stevens, C.D. (2010). Clinical Immunology and Serology.3rd ed. F.A .Davis Company .Philadelphia. 20:144.

[11]. Lynch, PLM.(2006). Audit of Cryoglobulin Determination in Northern Ireland . Clinical Biochemistry Department ,Altnagelvin Area Hospital, Londonderry . Full implementation of all new guidelines : 1-13.

[12]. Sargur, R. ; White, P. and Egner, W.(2010). Cryoglobulin evaluation: best practice. Ann ClinBiochem . 47: 8-16

[13]. Kallemuchikkal, U. and Gorevic, PD.(1999). Evaluation of cryoglobulins . Arch Pathol Lab Med .123: $119-25$.

[14]. Shnawa I.M.S. and Al-Gebori N.R.R.2012.Secretory and circulatory secondary cryoglobulinemia in pulmonary tuberculuspatients.Baby.Uni.J(.Pure and applied)22(1);1419-1427.

[15]. Shnawa IMS and Al-GheraniEFH 2014.The effect of aging on cryoglobulin responses on pulmonary tuberculosis patients.Baby.Uni.J.(Pure and and applied Science) 22(1):738-748.

[16]. Galli, M. ;Monti, G. ; Cereda, U.G. ; Del Giudice, G. ; Fiorenza, A.M. and Invernizzi, F.(1984). Transient symptomatic cryoglobulinemia in gram-negative bacteria infections.Boll IstSieroter Milan. 63(1):57-60.

[17]. 17-Eldar, M. ;Neeman, A. ; Shoenfeld, Y. and Pinkhas, J.(1980). Transient mixed cryoglobulinemia associated with typhoid hepatitis. New Istanbul ContribClin Sci. 13(1):55-57 . 